FECHA DE

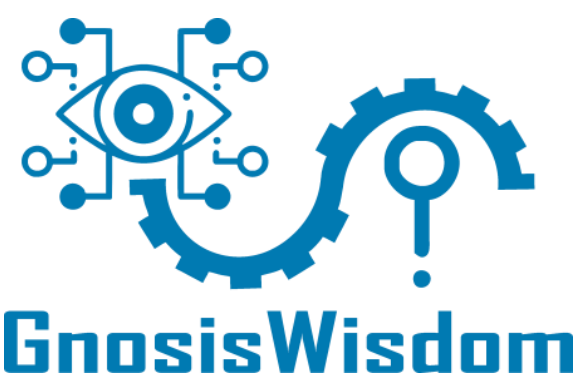

\section{REVISTA DE INVESTIGACIÓN E INNOVACIÓN CIENTÍFICA Y TECNOLÓGICA}

Artículo original

Volumen 1, Número 1, Enero-Abril 2021

\title{
RASGOS SEMIÓTICOS CÓSMICOS Y COTIDIANOS EN EL POEMARIO "KHIRKHILAS DE LA SIRENA" DE GAMALIEL CHURATA
}

\section{COSMIC AND EVERYDAY SEMIOTIC FEATURES IN THE POEMARY \\ "KHIRKHILAS DE LA SIRENA" BY GAMALIEL CHURATA}

\section{Autor}

Hilasaca Machaca, Alexander Wilber

UNIVERSIDAD NACIONAL DE CAÑETE

\section{Resumen}

Arturo Peralta, conocido con el seudónimo de "Gamaliel Churata", ha sido el escritor más importante de su época por su aporte decolonial e intercultural, mítico, filosófico, literario y lingüístico que sustentó las bases teóricas del pensamiento andino. El objetivo de esta investigación fue determinar los rasgos semióticos, cósmicos y cotidianos de su poemario Khirkhilas de la sirena. Se abordó desde la literatura interesándonos en el corpus poético. El método que se utilizó fue el semiótico y el diseño de investigación, descriptivo. Se aplicó la técnica de análisis de textos cuyo instrumento es la ficha de análisis. Los resultados que se determinaron muestran componentes narrativos, componentes figurativos y niveles profundos de semiótica. Mientras que en los rasgos cósmicos hay: deidades, ritos andinos y manifestaciones culturales. Y en los rasgos cotidianos se nota: valores e identidad cultural. Churata, a través del diálogo penetra en la naturaleza y recrea nuevas formas poéticas. Se concluye que los rasgos semióticos, cósmicos y cotidianos se da en la complementariedad de cuerpo y alma (ajayu), vida y muerte, eros y tánatos. Dicha relación se observa en la convivencia del hombre con la naturaleza y los valores que irradia la tierra.

Palabras clave: Churata, cósmico, cotidiano, rasgos y semiótica.

\begin{abstract}
Arturo Peralta, known by the pseudonym "Gamaliel Churata", has been the most important writer of his time for his decolonial and intercultural, mythical, philosophical, literary and linguistic contribution that supported the theoretical foundations of Andean thought. The objective of this research was to determine the semiotic, cosmic and everyday features of his collection of poems Khirkhilas de la sirena. It was approached from the literature, interested in the poetic corpus. The method used was the semiotic and the research design, descriptive. The text analysis technique
\end{abstract} pág. 15 


\section{GnasisWisdam}

was applied, the instrument of which is the analysis sheet. The results that were determined show narrative components, figurative components and deep levels of semiotics. While in the cosmic features there are: deities, Andean rites and cultural manifestations. And in everyday features you can see: values and cultural identity. Churata, through dialogue, penetrates into nature and recreates new poetic forms. It is concluded that the semiotic, cosmic and everyday features occur in the complementarity of body and soul (ajayu), life and death, eros and thanatos. This relationship is observed in the coexistence of man with nature and the values that the earth radiates.

Keywords: Churata, cosmic, everyday, features and semiotics.

\section{Introducción}

Gamaliel Churata, un poeta que exalta la autovaloración del hombre andino, es sin duda, el profeta que marcó el pensamiento mítico del ande. La mezcla de elementos lingüísticos y estéticos hace de su obra auténtica y original. El discurso poético churatiano se inserta en un contexto histórico-social cuya complejidad está caracterizada por la "situación colonial" (Bonfil, 1972). El proyecto poético que Churata había preparado era de gran magnitud dentro de ellos está el poemario "Khirkhilas de la sirena" también, "Mayéutica", "Baladas", "Haylli Inkásico y Biorritmias del Tawan" y "Batalla del diablo". La colección de poemas que integran siete volúmenes: Hararuñas del Chullpa-Thullu, El pez de oro, Resurrección de los muertos, Los pueblos Resucitan, Khosco-wara, Platón y el puma. El título "Khirkhilas de la sirena" es un neologismo para designar los "Rasgueos, bordoneos del Khirkhi, "charango, guitarrico hecho con la coraza del Khirkhinchu y de cordaje metálico" (Churata, 2017).

Asimismo, está poética es expresada como lo dice el propio Churata a través de una lengua "híbrida". Por eso, tal vez han considerado El Pez de Oro como un libro raro, precisamente porque no se comprende. La complejidad de la obra principal de Gamaliel Churata ha generado distintas vinculaciones: indígena (Huamán), surrealista indigenista (Gonzáles Vigil), barroca (Galdo) o una mezcla de todos estos componentes; esto por su carácter magmático (Mamani, 2012). La sirena, remonta al mito imaginario prehispánico, a la época matriarcal a través de los símbolos zoológicos. Estos "hombres de agua" como Churata los llama son un ejemplo de civilización que guarda estamentos matriarcales. La sirena, canta como un poeta remontando a la época matriarcal al que el autor afirma "que el idioma humano sea creación de la mujer" (Churata, 2010).

A partir de ello, determinamos una parte de su discurso poético, nos referimos a los 


\section{GnasisWisdam}

poemas del libro "Khirkhilas de la sirena" publicado póstumamente en el 2017 a cargo de Paola Mancosu. El poemario se divide en dos partes. La primera se compone de 15 poemas que son: Puma Bellica, Urpilila, Charankuni, Tiempo de wayñu, Acaba de parirle, Asina, Harawi, ¡Inka!, Tonito, Amaya thokhaña, Manemónica trascendetal del latido, Wayñusiña, Khollallali, Lajas de ayes y Me he perdido en tu carne. La segunda parte contiene un solo texto titulado "Wayñusiñas de la sirena" (Churata, 2017).

La semiótica se circunscribe al libro en el marco de lo "cósmico" y "cotidiano", impulsa a descifrar los símbolos que hay en cada poema. Ya que la semiótica la disciplina que se ocupa de la descripción científica de los signos y de los sistemas de significación, cualquiera que sea su materia significante" (Blanco \& Bueno, 1983). Es decir, se encarga de estudiar las diferentes formas de remisión. Existen objeto que han sido creados expresamente para hacer pensar en otros objetos, como las señales de tránsito, las notas musicales y las palabras de las lenguas "naturales". Existen otros objetos que se han convertido en signos de su propio uso social, a los que Barthes denomina "funciones-signos", tales como el automóvil, signo de velocidad o desplazamiento rápido; la máquina de coser, signo de costura; la tiza, signo de la clase (Eco, 1980). Si damos a la palabra "signo" un sentido genérico que engloba el de símbolo (que, por consiguiente, lo especifica), podemos decir que los estudios sobre el símbolo dependen de la teoría general de los signos. Lo cual, entronca en varias tradiciones distintas y aisladas, tales como la filosofía del lenguaje, la lógica, la lingüística, la semántica, la hermenéutica, la retórica, la estética, la poética (Todorov, 1993). Esta última responde a categorias semióticas como componente narrativo, componente figurativo, estados de trasnformación, roles actanciales y roles temáticos (Greimas, 1974).

La poesía de Churata repone en su cántico a lo cósmico y la figura totémica "la sirena" símbolo de la edad lunar y matriarcal, se asocia a menudo al Chullpa-thullu. Con el significado de cementerio en referencia de las estructuras funerarias de la región lacustre (Moncosu, 2013). En el mundo andino la creencia en deidades sobrenaturales y la religiosidad es antigua y se remonta a los propios comienzos de la historia humana. El ser divino en el contexto del hombre andino se manifiesta de diversas formas. Existen un sin número de deidades que tienen sus propias características y sus formas. Estas aparecieron en las tribus y había hombres capaces de conocer e interpretar estos sucesos naturales de la tierra, estudiaban los desastres naturales, las señales de los astros, las plantas medicinales, etc. (Muñoz, 2014). El ser humano andino, "cultivando" esta región peculiar, viene elaborando como expresión de la coexistencia con su medio natural, un modo 


\section{GnasisWisdam}

determinado de vivir, actuar y concebir" (Estermann, 2015). El cosmos es la casa y esta se relaciona con todos los demás elementos como el ser del runa (hombre) radica en ella mediante el trabajo, el trabajo es el medio para que el hombre sea hombre, este trabajo a la vez se hace en el ayllu, es decir en comunidad, de tal modo que el sujeto no es concebido como en occidente, en donde este concepto reemplaza prácticamente la concepción ontológica de la substancia, este concepto implica autonomía, espontaneidad, soberanía, individualidad, personalidad, responsabilidad y autenticidad a diferencia de este el hombre andino define su identidad a través de relaciones, es un puente o un nudo de múltiples relaciones, el centro de gravitación no es el individuo sino la comunidad en relación a la naturaleza y al conocimiento; todo ello bajo la búsqueda de la verdad propugnada por la filosofía (Velásquez, 2006). La concepción del mundo andino depende básicamente de dos elementos primarios: el tiempo y el espacio. Se considera la pacha (que se traduce como "tierra" pero que también significa "todo lo que es") como elemento que contiene el tiempo y el espacio, siendo la base común de distintos realidades como a kaypacha, el mundo real (la superficie de la tierra y del agua), la ukhupacha, el mundo bajo la tierra (la chinkhana y el chullpar en el fondo del lago Titicaca) así como la hananpacha (el cielo) constituyen la dicotomía hurin (ukhupacha) vs. awar (hananpacha), es decir una oposición entre abajo y arriba (Bosshard, 2014). Los principios giran entorno a la relación, la correspondencia, la complementariedad y la reciprocidad. Siendo el principio de relación un eje fundamental de la racionalidad andina, mientras el principio de complementariedad se sintetiza los principios de correspodencia y de relación porque ningún ser ni ninguna acción existe de manera aislada, sino que siempre coexiste con un complemento específico. El individuo se complementa con los demás, se encuentra en una relación unitaria. El principio de reciprocidad trae la acción de la solidaridad y la caridad. La ética tiene una dimensión cósmica (universal). El trueque practicado por civilizaciones esun buen ejemplo (Estermann, 2015).

En cambio "el puma" es otra figura totémica que se encuentra emparentada con la tradición amerindia. Al hablarnos desde una "voluntad mágica" encarnada tanto en El Pez de oro como también en el Khori-Puma (o Puma de Oro), la voz poética se enlaza con estos animales tal como lo hicieran los escritores del Chilam Balam. Se aprecia haber cubierto la hazaña en la realidad de las fenoménicas de la materia, pudiendo justificar la radical conclusión, que impone reconocer que su hazaña, en cuanto individuo zoótico" (Churata et al., 2017)

La muerte y el culto a los muertos un tema muy recurrente en la poética churatiana tiene 


\section{GnasisWisdam}

algunas variaciones, en las pequeñas ciudades andinas (por ejemplo, en Acora, Ilave, etc.), así, solo los familiares muy cercanos al difunto traen productos alimenticios y lo colocan alrededor de las tumbas, para regalarlos a los no familiares que vienen a rezar en cada tumba, es decir, la reciprocidad de alimentos entre todos los que participan en el rito. El rito también implica ofendrar con coca, alcohol, cigarrillos, caramelos, etc. La muerte de una persona también tiene además del dolor, una profunda significación para el hombre de andino (Claverias, 1990). El Ahayu dentro del universo de la necrademia donde un muerto no muere, sino que está vivo, que pervive en los seres que los aman o lo odian $\mathrm{y}$ en ellos sigue desplegando sus acciones.

En ese sentido, esa interioridad abstracta se revela y concreta en sus acciones, además de las revelaciones, ya sean por vías oníricas o por respuestas emocionales surgidas de momentos extremos como los accidentes (Mamani, 2015).

La pachamama, la madre tierra es un elemnto rector, como globalidad dadora de vida, matriz universal (Huamán, 1994). La "Pachamama" tiene rasgos de fecundidad que presenta como acento cultural en la obra de Churata, tamabién, como alteridad o fuerza resaltable.

"Madre tierra, es forma extraída del quechua-aymara. En qallawaya puquinazado es paqas" (Federico, 2000). Otro elemento singular que hace uso Churata es el agua (uma) El agua es un ser vivo, proveedor de vida y de animación del universo. Con el agua se dialoga, se le trata con cariño, se le cría. Esta visión ha sido factor fundamental para la adecuada cosecha, conservación y reproducción de los recursos hídricos. El agua proviene de Wirakocha, dios creador del universo, que fecunda la Pachamama (madre tierra) y permite la reproducción de la vida. Es, por tanto, una divinidad que está presente en los lagos, las lagunas, el mar, los ríos y todas las fuentes de agua (Scherbosky, Furlani, González, \& Carmona, 2013).

El universo es como la casa y pertenece a una sola familia bajo un solo techo. Fuera de la casa no hay nada; y dentro de ella, todo está relacionado a través de los ejes "espaciales" de arriba/abajo y derecha/izquierda. Así, lo confirma Estermann reafirmando la poética planteada por Churata.

Por lo tanto, el objetivo de la investigación fue determinar las categorías cósmicas y cotidianas del poemario "Khirkhilas de la sirena" de Gamaliel Charata, e identificar la relación que existe entre ambas categorías.

\section{MATERIALES Y MÉTODOS}

De acuerdo a los objetivos planteados la investigación fue realizada al corpus del 


\section{GnosisWisdam}

libro "Khirkhilas de la sirena" de Gamaliel Churata, se determinó las categorías cósmicas y cotidianas en los poemas: Puma bellica, urpilila, charankuni y asina. Se empleó el método del Análisis semiótico, propuesto por (Greimas, 1989) y aplicado por Desiderio Blanco y Raúl Bueno. Se tomó las siguientes categorías: Componente Narrativo. Componente Figurativo y el Nivel Profundo.

$\checkmark$ El análisis semiótico es un método de estudio que desarrollan los componentes narrativos, componentes figurativos $\mathrm{y}$ programas narrativos que pueden ser aplicados a varios discursos o textos como un relato, poesía, cine y publicidad. Además, de ser una disciplina científica es tributaria del positivismo: agota el conocimiento de los elementos que organiza el sentido de un discurso y establece las relaciones ocultas que los enlaza para producir el sentido (Blanco \& Bueno, 1983).

$\checkmark$ El modelo de interpretación consta de tres dimensiones: 1) Componente Narrativo, que comprende el modelo actancial 2) Componente Figurativo, que comprende los roles temáticos 3) Nivel Profundo, comprende los lexemas, semas $\mathrm{y}$ cuadrado semiótico.

Estas se aplicaron al corpus de estudio de la obra "Khirkhilas de la sirena" determinando las categorías cósmicas y cotidianas. La investigación es de tipo descriptivo, por ello se recogió la información actualizada como parte del proceso se revisó diferentes bibliografías para recabar información. La técnica de análisis de textos implicó adentrarnos al texto a través del instrumento de ficha de análisis.

\section{Ejes de análisis}

Tabla 1

Operacionalización de variables

\begin{tabular}{|c|c|c|}
\hline Unidad de análisis & Ejes de análisis & Sub ejes de análisis \\
\hline $\begin{array}{l}\text { 1. Rasgos semióticos, } \\
\text { cósmicos y } \\
\text { en elidianos } \\
\text { "Khirkhilas de } \\
\text { sirena" }\end{array}$ & $\begin{array}{l}\text { 2. Rasgos semióticos } \\
\text { 3. Rasgos Cósmicos } \\
\text { 4. Rasgos Cotidianos }\end{array}$ & $\begin{array}{l}\text { 2.1. Componente } \\
\text { narrativo. } \\
\text { 2.2. Componente } \\
\quad \text { figurativo. } \\
\text { 2.3. Nivel profundo } \\
\text { 3.1. Deidades } \\
\text { 3.2. Ritos } \\
\text { 4.1. Valores } \\
\text { 4.2. Identidad } \\
\end{array}$ \\
\hline
\end{tabular}

Fuente: Plan de investigación. 


\section{GnasisWisdam}

Tabla 2

Corpus de estudio.

\begin{tabular}{|c|c|}
\hline Libro & Poemas seleccionados \\
\hline Khirkhilas de la sirena & $\begin{array}{ll}\text { - } & \text { Puma Bellica } \\
\text { - } & \text { Urpilila } \\
\text { - } & \text { Charankuni } \\
\text { - } & \text { Asina }\end{array}$ \\
\hline
\end{tabular}

Fuente: Plan de investigación.

\section{RESULTADOS Y DISCUSIÓN}

La creación del poemario "khirkhilas de la sirena" de Gamaliel Churata es producto de la presencia de entidades cósmicas y cotidianas, que animan la realidad. Estas constituyen simbologías que se mezclan en la naturaleza así lo reafirma el mismo autor:

El puma es el personaje protagónico de El Alfabeto del Incognoscible, "se aprecia haber cubierto la hazaña en la realidad de las fenoménicas de la materia, pudiendo justificar la radical conclusión, que impone reconocer que su hazaña, en cuanto individuo zoótico" (Churata et al., 2017).

"El Puma" es la figura totémica la voz poética se enlaza con este animal tal como lo hicieran los escritores del Chilam Balam. En efecto, la figura del puma como símbolo de poder, es un protagonista que batalla por reivindicar la cultura andina.
Para explicar mejor, esta categoría del poema titulado "puma bellica": determinemos los rasgos semióticos.

El componente narrativo

El poema, presenta la condición narrativa, sostenida por los siguientes verbos de acción: labra, guerrean, levitación, zarpa, acomete, acaba, devora, ordeñaré, volverá, levantará. Por ende, lo clasificamos en la categoría de relato. Para lo cual, vamos a develar su fundamento narrativo.

Modelo actancial

En el desarrollo del poema se notan los siguientes actantes: "Sirena" y "Puma". Ambos desempeñan roles actanciales: “ ... la sirena / espuma de arpías de las olas." , "fragante estoy en el dintel de tus ovarios/ cimbro, amor, temerario y fragante." “jordenaré las mamas de la chullpa / y phusará la phusa de tu ñuñu..." “de las tumbas volverá la sirena/ levantará mi garra la raíz de su aroma.”. En ellos se nota la presencia de dos sujetos con relación a un mismo 


\section{GnasisWisdam}

objeto de comunicación (el nacimiento).

Respecto al objeto, se produce "una acción de renacer, de resucitar, de reconstrucción, guerra"; de ahí que esos dos actantes sujetos hayan merecido las desiganciones especiales de destinador y destinatario, respectivamente. Por su naturaleza, el eje que los vincula recibe el nombre de eje de la comunicación. Definido los actantes, simplificaremos mediante una notación simbólica, para que pueda dar cuenta de su descripción semiótica.

Sujeto Sirena (A1)

Objeto Guerra (A2)

Destinador Puma (A3)

Destinatario El hombresociedad andina (A4)

Oponente Muerte (A5)

Ayudante Vida (A6)

Así, la sirena y el puma (S1) desempeñan los roles actanciales: son los sujetos instaurados de deseo, por referencia al objeto/ guerra, que con su hacer reflexivo impulsa a ganar a la muerte (Wawaku) que culmina en la conjunción con su objeto de deseo y objeto realizado como existencia vital, continuidad y permanencia: "volverá la Sirena;/ levantará mi garra la raíz de su aroma.”

Con respecto al destinador, los sujetos operadores llevan este saber (mandato) a la sociedad andina, al hombre para que no teman a la muerte, ya que ella no existe independientemente de la vida, la muerte necesita de la vida cuando uno muere solo muere el cuerpo, no la muerte: “...la muerte acomete con su lobo de fuego". El destinador (puma) cuando implanta su deseo sobre la muerte para vencerlo, implanta su triunfo.

El oponente es la "muerte" Churata dice: "para estos pueblos la muerte es un mito y ese mito en manos de las religiones positivas el fundamento de la dualidad de Esencia y Sustancia como factores de la dialécticos de la conciencia humana" es decir, la muerte en esencia no existe. La muerte no es una vía para eludir las responsabilidades en la tierra, porque siempre se estará en ella, aunque con una presencia distinta. El tema de la muerte se vincula a los procesos económicosociales por los que atraviesa el pobre, específicamente a la especulación (Mamani, 2015). La semilla del muerto influiría en el vivo con consecuencias tan positivas como negativas. Recordemos que el espacio aymara se organiza en tres pachas: el Alax Pacha o mundo de arriba, dominio del dios Sol y su mujer la Luna, el Manqa Pacha o mundo de abajo y el Aka Pacha el mundo de los vivos. Sin 


\section{GnasisWisdam}

embargo, esta última división entre el Manqa Pacha y el Aka Pacha no queda muy definida como espacios separados, diversos y contrapuestos. Más bien, formarían parte de un espacio compartido en el que el Manqa Pacha poseería una carga metafórica escondida a la que los vivos no tendrían acceso; es allí donde radica la separación de los mundos. Sin embargo, la moral aymara no ubica a los buenos en el Alax Pacha y a los malos en el Manqa Pacha. El universo aymara se organiza en la dualidad, la bipolaridad de opuestos que juntos forman un todo, por lo tanto, ningún mal es absoluto, ninguna bondad eterna, los dos opuestos componen la naturaleza y el hombre (Hermoza, 2017).

En cuanto concierne al Ayudante "vida" para Churata la vida es dependiente de la muerte, y es la forma de demostrar la existencia de la muerte. La articulación semántica de esta relación está dada por: deseo, poder y saber. El deseo del sujeto "Puma, sirena" por vencer en batalla a la muerte, para prevaleer en el ciclo vital de la tierra. El poder del oponente y ayudante permite la disyunción: muerte $\checkmark$ vida, "fragante estoy en el dintel de tus ovarios". Finalmente, se traslada un saber del sujeto "puma" al hombre andino o sociedad andina "¡Espera mamitay: ya la guerra se labra!..."

La vida como "ser en mónada", según la concepción de Churata, requiere entonces unidad. La condición ineluctable de la vida es la unidad, una unidad que se realiza a través de la unión corporal y que resulta discernible sintiendo. En este acto de sentir, el yo siempre se refiere recíprocamente a un tú, sin el cual el yo no puede existir (Bosshard, 2007).

En suma, el poema "Puma bellica" no es otra cosa que una trasformación y el estado disyuntivo motivado por esta. Estado 1: S1 $\vee \mathrm{O}$ (objeto realizado)

Trasnformación:<smiles>O[SiH2][SiH2][SiH2][SiH2][SiH2][SiH3]</smiles>

Como la transformación es de naturaleza reflexiva y termina en la conjunción con el objeto, la calificaremos de aproximanción triunfal.

\section{Componente figurativo: Los actores y} sus roles temáticos

A los símbolos $\mathrm{S} 1$ y $\mathrm{S} 2$ de nuestra descripción del poema "Puma bellica" corresponden, a dos actores o personajes antropomórficos del relato contenido en el texto: Puma y la Sirena. Ellos se hacen cargo de los roles actanciales 
Volumen 2, Número 1, Enero-Abril 2021 Fecha de publicación: 15-03-2021 - Fecha de aceptación:14-02-2021

\section{GnasisWisdam}

considerados procedentemente, según la cual un mismo actor puede tener a su cargo uno o varios roles actanciales. El "Puma Bellica" del poema de Churata desempeña, según nos lo hacen ver las figuras de acciones y comportamientos del texto los siguientes roles temáticos: "anunciador”, "guía”, "mensajero”. La Sirena, desmepeña los roles: "guiada", "anunciada", "informada" y “empoderada". Los actores constituyen un "puente" o nexo entre los roles del componente narrativo (actanciales) y las del componente figurativo (temáticos).

Los roles temáticos advertidos en el poema de Churata corresponde evidentemente a algunos de los roles actanciales descubiertos en la parte mencionada, según puede observarse en los cuadros siguientes:

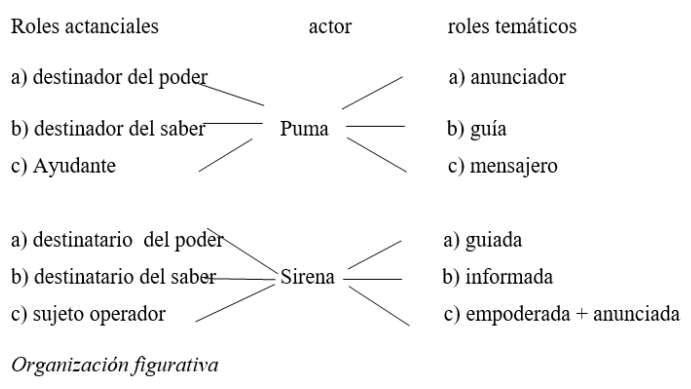

El rol temático “anunciador" está ampliamanete sostenido en el texto por una diversidad de figuras sémicas, entre las que resaltan las siguientes: "guerrean", "labra", "fragante", "devorando", "hambrura", “ordeñaré", "mamas", "volverá” y "levantará”. El rol temático "guiada" se sostiene en las mismas figuras anteriores. Ellas conforman la configuración discursiva de el triunfo de la batalla, de la cual el Puma es destinador del deseo y la Sirena, la sociedad andina y el hombre son destinatarios. El rol temático “anunciador", por último, está principalmente soportado por las figuras que se encuentran en el enunciado “¡Espera, mamitay:/ ya la guerra se labra!"

\section{Nivel profundo}

A nivel profundo, el lexema "Sirena" genera los semas: /ovarios/, /ñuños/, /matriarcado/, /madre/. El lexema "Puma" genera los semas: /progenitor/, /patriarcado/, /bestía/, /padre/. En esta primera aproximación diremos que el Puma y la Sirena son complementos para mantener la continuidad vital de la vida, además de habitar y resguardar el mundo de arriba y el mundo de abajo.

El los semas del segundo grupo tenemos el lexema "Muerte" que genera los semas: /tumbas/, /estertor/, /daño/, /sufrimiento/. El lexema "vida" genera los semas: /escencia/, /vitalidad/, /existencia/, /savia/, /subsistencia/. Estos 


\section{GnasisWisdam}

semas constituyen la resurreción y la superación entre la vida y la muerte.

\section{Estrucutra elemental}

Aplicando el modelo del cuadrado semiótico, podemos observar el juego de las isotopías en que se mueve el texto, por un lado, contamos con los semas de /madre/ y /padre/, que constituyen los términos opuestos de un eje sémico.

La categoría sémica puesta en marcha por dichos términos es la de /protección/. Un primer cuadrado semiótico puede ser establecido con estos términos:

Protección

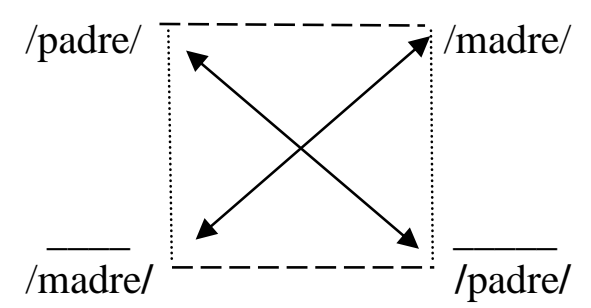

Figura 1. Cuadro semiótico sobre la protección

Fuente: Greimas (1989).

Por otro lado, encontramos el sema nuclear /vida/. El término contrario en el eje sémico que corresponde es /muerte/. Este sema está realizado de forma directa en el texto, lo cual permite generar profundida en el poema. El sema /vida/ lo entendemos por su oposición al sema /muerte/. la presencia de vida implica la negación de muerte. Tenemos un segundo cuadro semiótico.

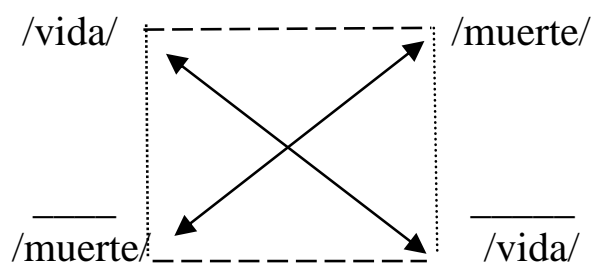

Figura 2. Cuadrado semiótico

sobre la vida y la muerte

Fuente: Greimas (1989).

Es así que la muerte no sería sino una "ficción de la palabra", como dice Riccardo Badini (1997) y los ancestros seguirían viviendo en la tierra en forma de hata o semilla. El espacio, fuertemente marcado por su herencia ancestral, se vuelve entonces el escenario donde convive el pasado, el presente y el futuro. El autor logra así despojarse de toda lógica temporal pues, según él, "tampoco existe el tiempo y se vive en profundidad espacial". Al eliminar la idea de la muerte, la filosofía de Churata se torna una filosofía de la afirmación pues para Churata es esencial el "afirmar, hoy, mañana y siempre" (Velasco, 2016).

El poema nos conlleva a una categoría cósmica y cotidiana a través de la simbología, una característica marcada en la obra de Churata. La mezcla del español con elementos lingüísticos como el aymara y el quechua hacen auténticas la obra. Bonfil (1972) lo reafirma haciendo hincapié en su discurso 


\section{GnasisWisdam}

poético, y nos dice: gracias a ello se inserta en el contexto histórico-social.

Como lo manifiesta Paola Moncosu "La sirena símbolo de la edad lunar y matriarcal, se asocia a menudo al Chullpa-thullu" La sirena, es un sujeto operador que lleva este saber (mandato) a la sociedad andina, al hombre para que no teman a la muerte, ya que ella no existe independientemente de la vida, la muerte necesita de la vida cuando uno muere solo muere el cuerpo, no la muerte: "...la muerte acomete con su lobo de fuego". El destinador (puma) cuando implanta su deseo sobre la muerte para vencerlo, implanta su triunfo.

La sirena remonta al mito imaginario prehispánico. Estos "hombres de agua" como (Churata, 2010) menciona son un ejemplo de civilización que guarda estamentos matriarcales. La sirena, canta como un poeta remontando a la época matriarcal al que el autor afirma "que el idioma humano sea creación de la mujer.

Los estudios de Paola Moncosu entorno a las "Fluctuaciones míticas: las sirenas de Gamaliel Churata. Analiza la sirena desde un sistema de género-otro que se asienta en la reciprocidad andina entre masculino y femenino y halla su raíz en las antiguas sociedades matriarcales americánas y europeas. La imagen de la "sirena" es una disyunción social e histórica entre cultura, naturaleza, razón, cuerpo, sujeto y objeto.

A los símbolos $\mathrm{S} 1$ y $\mathrm{S} 2$ de nuestra descripción del poema "Puma bellica" corresponden, a dos actores o personajes antropomórficos del relato contenido en el texto: Puma y la Sirena. Ellos se hacen cargo de los roles actanciales considerados procedentemente, según la cual un mismo actor puede tener a su cargo uno o varios roles actanciales. El "Puma Bellica" del poema de Churata desempeña, según nos lo hacen ver las figuras de acciones y comportamientos del texto los siguientes roles temáticos: "anunciador", "guía", "mensajero". La Sirena, desmepeña los roles: "guiada", "anunciada", "informada" y “empoderada". Los actores constituyen un "puente" o nexo entre los roles del componente narrativo (actanciales) y las del componente figurativo (temáticos). Ambos actores, se organizan en base al ayllu como (Estermann, 2015) afirma que las civilizaciones quechuas $\mathrm{y}$ aymaras, se organizaban en base al ayllu, practicando el principio de reciprocidad y de complementariedad.

Asimismo, Velásquez (2006) explica que el cosmos es la casa y esta se 


\section{GnasisWisdam}

relaciona con todos los demás. Ambos sujetos (Puma y Sirena) radican en el ella. El hombre andino define su identidad a través de relaciones, es un puente o un nudo de múltiples relaciones. Practica principios como correspondencia, complementariedad y reciprocidad.

A nivel profundo, el lexema "Sirena" genera los semas: /ovarios/, /ñuños/, /matriarcado/, /madre/. El lexema "Puma" genera los semas: /progenitor/, /patriarcado/, /bestía/, /padre/. En esta primera aproximación diremos que el Puma y la Sirena son complementos para mantener la continuidad vital de la vida, además de habitar y resguardar el mundo de arriba y el mundo de abajo. La concepción del mundo andino depende de dos elementos primarios nos dice (Bosshard, 2014) las cuales son: tiempo y espacio.

El estudio de (Claverias, 1990) sobre el rito en el día de los muertos están enfocado desde el ciclo del retorno. El rito a la "vuelta" de los muertos, en los primeros días de noviembre, es otra ilustración del cambio de categorías en el modo de pensar andino; auqnue, estos cambios no significan la destrucción total de los conceptos básicos del pensamiento andino.
Para el runa/jaqi, vida y muerte son realidades complementarias y no opuestas o antagónicas: donde hay 'muerte' (el fin de algo viejo), ahí mismo también hay 'nacimiento' (el inicio de algo nuevo); esta experiencia se refleja en la concepción andina del tiempo que es circular o cíclica: inicio y fin coinciden ('los extremos se tocan').

En suma, el poema "Puma bellica" no es otra cosa que una trasformación y el estado disyuntivo motivado por esta. Cuyo signo se utiliza para transmitir una información, para decir o para indicar a alguien algo que otro conoce y quiere que lo conozcan los demás también, es decir que el signo se considera en relación con lo que significa (Eco, 1980).

\section{Conclusiones}

Todo el poemario de Churata, "Khirkhilas de la sirena", es producto de la presencia de las entidades cósmicas y cotidianas; Estos seres antropomórficos, seres del mundo animal, seres provenientes del mundo natural son deidades que anuncian el regreso del nuevo mundo para recobrar la identidad y los orígenes históricos. Las deidades están relacionadas con los ritos a la Pachamama, los pagos al agua y el rito a los muertos. (La vida en el mundo andino 


\section{GnasisWisdam}

es cíclica). Aparecen los ritos en el poemario relacionados con la vitalidad del hombre. Asimismo, La relación entre los rasgos cósmicos y cotidianos se da en la contradicción semiótica de cuerpo y alma (ajayu), vida y muerte, eros $\mathrm{y}$ tánatos, individual y colectivo. Dicha relación también se observa en la complementariedad entre el animal y el hombre, la naturaleza y la convivencia.

En cuanto a los rasgos cotidianos que se identificaron fueron Sol, mamas, guagua, phusiris, uma, wayñusina, harawis, khaswe, kharachis, alba y asinita. Estos rasgos pertenecientes al mundo andino recobran los valores y la identidad. En ellas también se da la ritualidad como el respeto a la naturaleza, el buen vivir, los valores que se practican en la ceremonia y mantienen la cultura y la tradición.

La relación entre los rasgos cósmicos y cotidianos se da en la contradicción semiótica de cuerpo y alma (ajayu), vida y muerte, eros y tánatos, individual y colectivo. Dicha relación también se observa en la complementariedad entre los animales y el hombre, la naturaleza y la convivencia. El hombre andino, siendo parte de la tierra, irradia valores como la reciprocidad.

\section{Referencias}

Blanco, D., \& Bueno, R. (1983). Metodología del análisis semiótico. Lima-Péru: Universidad de Lima.

Bonfil, B. G. (1972). El concepto de indio en América: Una categoría de la situación colonial. Anales de Antropología, (9), |05-124.

Bosshard, M. T. (2007). Mito y mónada: La cosmovisión Andina como base de la estética vanguardista de Gamaliel Churata. Revista Iberoamericana. 20, 515-539.

DOI: https://doi.org/10.5195/reviberoa mer.2007.5356

Bosshard, M. T. (2014). Churata y la Vanguardia andina. Lima, Perú: CELACP Latinoamericana editores.

Churata, G. (2010). Resurrección de los muertos. Lima: Asamblea Nacional de Rectores.

Churata, G. (2017). Khirkhilas de la sirena. La Paz, Bolivia: Plural.

Claverias, H. R. (1990). Cosmovisión y planificación en las comunidades andinas. Lima: Producción Dugrafys.

Eco, H. (1980). Signo. Barcelona: Labor.

Estermann, J. (2015). Filosofía andina. Estudios intercultural de la sabiduría andina. Quito: Ediciones Abya-Yala.

Federico, A. (2000). El idioma del pueblo 
Volumen 2, Número 1, Enero-Abril 2021 Fecha de publicación: 15-03-2021 - Fecha de aceptación:14-02-2021

\section{GnasisWisdam}

Puquina. Un enigma que va aclarándose. Quito: El fondo ecuatoriano Popolorum Progressio.

Greimas, A. (1974). En torno al sentido. Barcelona: Fragua.

Greimas, A. (1989). Del sentido. Madrid: Gredos.

Hermoza, L. (2017). La ruta del ahayu watan: realismo psíquico para leer El pez de oro (1957) de Gamaliel Churata. Mitologías Hoy: Revista de Pensamiento, Crítica y Estudios Literarios Latinoamericanos.

Huamán, M. A. (1994). Fronteras de la escritura. Discurso y utopía en Churata. Lima-Perú: Horizonte.

Kristeva, J. (1981). Semiótica 2. Madrid: Espiral.

Luque, W. K. (2014). Gamaliel Churata / Textos esenciales. Tacna, Péru: Editorial Korekhenke.

Mamani, M. (2012). Quechumara. Proyecto estético-ideológico de Gamaliel Churata. Perú: Fondo editorial de la Universidad de Ciencias y Humanidades.

Millones, L. (2014). Las sirenas de Sarhua. Revista Letras, (75), 15-31. Lima, Perú.

Mamani, M. (2015). Ahayu-watan: una categoría andina para explicar nuestra cultura. Caracol, 1(9), 92-127. https://doi.org/10.11606/issn.2317-

9651.v1i9p92-127

Moncosu, P. (2013). Fultuaciones míticas: Las sirenas de Gamaliel Churata. Contextos Revista Crítica de Literatura, 103-123.

Muñoz, P. L. (2014). Categorias andinas para una aproximación al Willakuy. Lima: Asamblea Nacional de Rectores.

Ortiz, J. C. (2007). El signo ideológico en la cultura aimara a través de los cuentos orales: Un estudio semiótico. (tesis de maestría). Escuela de Posgrado, Universidad Nacional del Altiplano de Puno, Puno, Péru. Recuperada de: http://repositorio.unap.edu.pe/handle/ UNAP/699

Palacios, C. G. (2016). El pensamiento social andino: una alternativa al modelo occidental de inclusión social. Revista Temática. Centro de altos estudios nacionales, (2), 135-159.

Pantigoso, M. (1999). El ultraorbicismo en el pensamiento de Gamaliel Churata. Perú: Universidad Ricardo Palma.

Pierce, C. (1974). La ciencia de la semiótica. Buenos Aíres: Ediciones nueva visión. Rubio, D. de T. (1966). Arte de la lengua aymara. Lima: Lyrsa.

Scherbosky, R. I., Furlani, N. S., González, C., \& Carmona, A. (2013). NUEVOS PARADIGMAS-VISION ANDINA 


\section{REVISTA DE INVESTIGACIÓN E INNOVACIÓN}

CIENTÍFICA Y TECNOLÓGICA

Volumen 2, Número 1, Enero-Abril 2021 Fecha de publicación: 15-03-2021 - Fecha de aceptación:14-02-2021

\section{GnasisWisdam}

DEL AGUA XLIV Reunión Anual

AAEA - San Juan 2013. 1-13.

Soto, K. (2016). América, adentro, más adentro. La geografía de Gamaliel Churata. Revista Recial, 9 (7), 1-11.

Todorov, T. (1993). Teorías del símbolo. Barcelona: Monte Avila Editores.

Usandizaga, H. (2009). El pez de oro, de Gamaliel Churata, en la tradición de la literatura peruana. América Sin Nombre.

https://doi.org/10.14198/amesn2009.1 3-14.18

Velásquez, J. L. (2006). El hombre y el cosmos en la concepción filosófica andina. Ediciones Inka Rojo: Lima, Perú.

Vilchis, A. (2008). Arturo Peralta Miranda: Travesía de un itinerante. México: América nuestra Rumi Maki.

Villca, M., \& Angelina, M. (2012). Redalyc.El discurso religioso en el aymara de Bertonio y el discurso ritual en el aymara de la provincia Camacho. Revista Ciencia y Cultura. (28), 237261. La Paz, Bolivia.

Zevallos, U. (2013). Indigenismo y nación. Puno, Perú: Universidad Nacional del Altiplano.

Scherbosky, R. I., Furlani, N. S., González, C., \& Carmona, A. (2013). NUEVOS PARADIGMAS-VISION ANDINA
DEL AGUA XLIV Reunión Anual AAEA - San Juan 2013. 1-13.

Soto Velasco, K. (2016). América, adentro, más adentro. La geografía de Gamaliel Churata. Recial, 9(7), 1-11.

Todorov, T. (1993). Teorías del símbolo. Barcelona: Monte Avila Editores.

Velásquez, J. L. (2006). El hombre y el cosmos en la concepción filosófica andina (Ediciones Inka Rojo, ed. Lima, Perú.

Vilchis, A. (2008). Arturo Peralta Miranda: Travesía de un itinerante. México: América nuestra Rumi Maki.

Villca, M., \& Angelina, M. (2012). Redalyc.El discurso religioso en el aymara de Bertonio y el discurso ritual en el aymara de la provincia Camacho. Revista Ciencia y Cultura. (28), 237261. La Paz, Bolivia.

Zevallos, U. (2013). Indigenismo y nación. Puno, Perú: Universidad Nacional del Altiplano.

\section{CORRESPONDENCIA:}

Hilasaca Machaca, Alexander Wilber alexkarnak@hotmail.com 